\title{
Redox and nutrient fluctuations in interglacial Neoproterozoic Witvlei Group carbonates (Namibia) argue for ecosystem instability promoting animal evolution
}

\author{
SimON V. HOHL ${ }^{1}$, AlEXANDRA RODLER ${ }^{2}$, ClAUdiO \\ GAUCHER $^{3} \&$ ROBERT FREI ${ }^{4}$ \\ ${ }^{1}$ State Key Laboratory of Marine Geology, Tongji University \\ Shanghai, PR China \\ ${ }^{2}$ AMGC, Vrije Universiteit Brussel, Brussels, Belgium \\ ${ }^{3}$ Facultad de Ciencias, Universidad de la República, \\ Montevideo, Uruguay \\ ${ }^{4}$ Dept. of Geosciences and Natural Resource Management, \\ University of Copenhagen, Copenhagen, DK
}

The Neoproterozoic witnessed several low latitude glaciations and geochemical and paleontological evidence hint at vast environmental changes that led to the evolution of multicellular life along with deep ocean oxygenation. Recent findings from trace element and novel stable isotope geochemistry argue for rather fluctuating than step-wise oxygenation of the deep Proterozoic oceans. The resulting ecosystem instability may have promoted the evolution of diverse new life forms.

In order to further test this hypothesis, we present new highresolution trace element, stable and radiogenic isotope data from carbonate sediments deposited in interglacial marine shelf environments of the Witvlei Group, Namibia.

Shale normalised REY patterns are parallel to modern oxidised seawater with HREY over LREY enrichments, positive $\mathrm{La}$ and negative $\mathrm{Ce}$ anomalies as well as superchondritic $\mathrm{Y} / \mathrm{Ho}$ ratios. $\delta^{13} \mathrm{C}_{\text {carb }}$ values range from -2 to $-5 \%$ and show no correlations with $\delta^{18} \mathrm{O}_{\text {carb }}$ and $\mathrm{Sr} / \mathrm{Mn}$ arguing against substantial diagenetic carbonate overprint. While concentrations of redox-sensitive $\mathrm{Mn}, \mathrm{Fe}, \mathrm{V}$ and $\mathrm{Cr}$ show variable and elevated values, concentrations of bioavailable $\mathrm{Ni}, \mathrm{Cd}$ and $\mathrm{Cu}$ are low but correlated. $\mathrm{Sr}$ and $\mathrm{Nd}$ isotopes show radiogenic values in carbonates deposited after the two global (and a potential third local) glaciations and a rebound to presumably global $\mathrm{Sr}$ and local $\mathrm{Nd}$ isotope compositions.

First $\mathrm{Cr}$ isotope data of carbonates overlying Sturtian glacial deposits are in the range of bulk silicate Earth, while shallow subtidal carbonates deposited after the Marinoan glaciation show pronounced positively fractionated $\delta^{53} \mathrm{Cr}$ values (up to $+0.7 \%$ ). We propose dynamic interglacial redox and nutrient variations as a trigger for accelerated primary productivity in the Witvlei Group shelf environment predating the Cambrian bio radiation. 